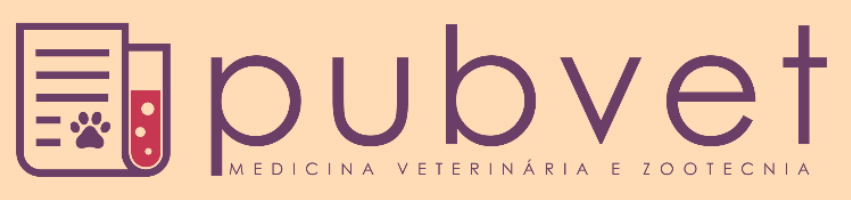

https://doi.org/10.31533/pubvet.v14n9a652.1-6

\title{
Linfoma multicêntrico em felino doméstico: Relato de caso
}

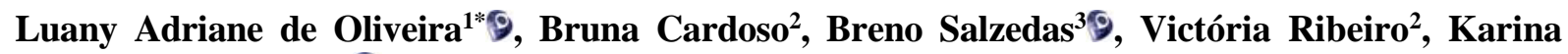 \\ D'Elia Albuquerque $\sqrt{4}$
}

${ }^{1}$ Graduanda em medicina veterinária pela Universidade Guarulhos

${ }^{2}$ Médica veterinária com residência em clínica médica de pequenos animais pela Universidade Guarulhos

${ }^{3}$ Médico veterinário com residência em patologia animal pela Universidade Guarulhos

${ }^{4}$ Médica veterinária e docente da Universidade Guarulhos

*Autor para correspondência: E-mail: luanyadriane@gmail.com

Resumo. Linfomas são neoplasias caracterizadas pela proliferação clonal de linfócitos malignos, originando-se principalmente de órgãos linfoides, como a medula óssea, baço e linfonodos. De acordo com a terminologia humana, os linfomas que ocorrem nos animais domésticos são conhecidos como não Hodgkin, cujo comportamento biológico, epidemiologia, morfologia celular e fenotipagem são bastante similares entre os seres humanos e os pequenos animais. O linfoma é a neoplasia felina mais comum, compreendendo mais de $50 \%$ de todos os tumores hemolinfáticos. Não se conhece a etiologia precisa do linfoma felino em muitos casos, entretanto, causas virais são bem definidas, havendo infecções tanto pelo vírus da leucemia felina (FeLV) quanto pelo vírus da imunodeficiência felina (FIV). Quando o linfoma é causado pelo FeLV, normalmente está associado com infecção progressiva, mas infecções regressivas também podem estar envolvidas na formação tumoral, cujo o vírus não é detectado pelo teste de ELISA, mas na PCR (sangue periférico ou medula óssea) é encontrado o DNA do provírus FeLV, isso sugere que o vírus pode estar associado com uma proporção maior de linfomas do que o esperado. Tais neoplasias podem apresentar-se em diferentes localizações anatômicas sendo classificado em multicêntrico, mediastinal (ou tímico), alimentar e extranodal (linfoma cutâneo, nasal, renal e em sistema nervoso). Nos gatos, a forma mediastinal e alimentar são mais comuns que a multicêntrica e a extranodal. O presente trabalho tem como objetivo apresentar o relato de caso de um felino doméstico, macho, SRD, 1 ano de idade e FIV/FeLV negativo no ELISA, apresentando aumento de linfonodos periféricos (submandibulares, inguinais e poplíteos) e aumento de linfonodos hepáticos, pancreatoduodenal, ilíaco medial, cólico e mesentérico. Foi realizado citologia do linfonodo submandibular onde foi diagnosticado linfoma imunoblástico. $\mathrm{O}$ paciente foi submetido ao protocolo quimioterápico CHOP (Ciclofosfamida, Doxorrubicina, Vincristina e Prednisolona) por 24 semanas, recebendo alta após esse período.

Palavras-chaves: gato, fiv/felv, linfoma, oncologia

\section{Multicentric lymphoma in domestic feline: Case report}

Abstract. Lymphomas are neoplasms characterized by the clonal proliferation of malignant lymphocytes, originating mainly from lymphoid organs, such as bone marrow, spleen and lymph nodes. According to human terminology, lymphomas that occur in domestic animals are known as non-Hodgkin, whose biological behavior, epidemiology, cell morphology and phenotyping are quite similar between humans and small animals. Lymphoma is the most common feline neoplasia, comprising more than $50 \%$ of all hemolymphatic tumors. The precise etiology of feline lymphoma is not known in many cases; however, viral causes are well defined, with infections by both feline leukemia virus (FeLV) and feline immunodeficiency virus (FIV). When lymphoma is caused by FeLV, it 
is usually associated with progressive infection, but regressive infections can also be involved in tumor formation, whose virus is not detected by the ELISA test, but in PCR (peripheral blood or bone marrow) is found FeLV provirus DNA, this suggests that the virus may be associated with a higher proportion of lymphomas than expected. Such neoplasms can present in different anatomical locations being classified into multicentric, mediastinal (or thymic), alimentary and extranodal (cutaneous, nasal, renal and nervous system lymphoma). In cats, mediastinal and alimentary forms are more common than multicentric and extranodal forms. The present work aims to present the case report of a domestic feline, male, SRD, 1 year old and FIV / FeLV negative in the ELISA, showing an increase in peripheral lymph nodes (submandibular, inguinal and popliteal) and an increase in liver lymph nodes, pancreatoduodenal, medial, colic and mesenteric iliac. Submandibular lymph node cytology was performed where immunoblastic lymphoma was diagnosed. The patient was submitted to the CHOP chemotherapy protocol (Cyclophosphamide, Doxorubicin, Vincristine and Prednisolone) for 24 weeks, being discharged after this period.

Keywords: cat, fiv / felv, lymphoma, oncology

\section{Linfoma multicéntrico en felino doméstico: Reporte de caso}

Resumen. Los linfomas son neoplasias caracterizadas por la proliferación clonal de linfocitos malignos, que se originan principalmente de órganos linfoides, como la médula ósea, el bazo y los ganglios linfáticos. Según la terminología humana, los linfomas que se producen en animales domésticos se conocen como no Hodgkin, cuyo comportamiento biológico, epidemiología, morfología celular y fenotipado son bastante similares entre humanos y animales pequeños. El linfoma es la neoplasia felina más común, que comprende más del $50 \%$ de todos los tumores hemolinfáticos. La etiología precisa del linfoma felino no se conoce en muchos casos, sin embargo, las causas virales están bien definidas, con infecciones tanto por el virus de la leucemia felina (FeLV) como por el virus de la inmunodeficiencia felina (FIV). Cuando el linfoma es causado por FeLV, generalmente se asocia con una infección progresiva, pero las infecciones regresivas también pueden estar involucradas en la formación de tumores, cuyo virus no se detecta mediante la prueba ELISA, sino en la PCR (sangre periférica o médula ósea). ADN del provirus FeLV, esto sugiere que el virus puede estar asociado con una mayor proporción de linfomas de lo esperado. Estas neoplasias pueden presentarse en diferentes ubicaciones anatómicas clasificadas en multicéntricas, mediastínicas (o tímicas), alimentarias y extranodales (linfoma cutáneo, nasal, renal y del sistema nervioso). En los gatos, las formas mediastínicas y alimentarias son más comunes que las formas multicéntricas y extranodales. El presente trabajo tiene como objetivo presentar el informe del caso de un felino doméstico, varón, SRD, 1 año de edad y FIV / FeLV negativo en el ELISA, mostrando un aumento en los ganglios linfáticos periféricos (submandibular, inguinal y poplíteo) y un aumento en los ganglios linfáticos hepáticos, pancreatoduodenal, medial, cólico e iliaco mesentérico. La citología de los ganglios linfáticos submandibulares se realizó donde se diagnosticó el linfoma inmunoblástico. El paciente fue sometido al protocolo de quimioterapia CHOP (ciclofosfamida, doxorrubicina, vincristina y prednisolona) durante 24 semanas, siendo dado de alta después de este período.

Palabras clave: gato, fiv / felv, linfoma, oncología

\section{Introdução}

As neoplasias são uma das principais causas de morte em pequenos animais (Yazbek, 2008). A incidência de lesões oncológicas tem aumentado nos últimos anos. Este aumento ocorre por várias razões, sendo uma das principais a maior longevidade dos animais de companhia (Withrow, 2001). Linfomas são neoplasias caracterizadas pela proliferação clonal de linfócitos malignos, originando-se principalmente de órgãos linfoides, como a medula óssea, baço e linfonodos. De acordo com a terminologia humana, os linfomas que ocorrem nos animais domésticos são conhecidos como não 
Hodgkin, cujo comportamento biológico, epidemiologia, morfologia celular e fenotipagem são bastante similares entre os seres humanos e os pequenos animais (Daleck \& Nardi, 2016).

O linfoma é a neoplasia felina mais comum, compreendendo mais de 50\% de todos os tumores hemolinfáticos, pode acometer felinos de qualquer idade, sexo ou raça, embora os gatos de raça pura, como Manx, Birmanês e Siamês possam ter risco maior. Não se conhece a etiologia precisa do linfoma felino em muitos casos, entretanto, causas virais de linfoma felino são bem definidas, havendo infecções tanto pelo vírus da leucemia felina (FeLV) quanto pelo vírus da imunodeficiência felina (FIV) (Choy \& Bryan, 2016).

Tais neoplasias podem apresentar-se em diferentes localizações anatômicas sendo classificado em multicêntrico, mediastinal (ou tímico), alimentar e extranodal (linfoma cutâneo, nasal, renal e em sistema nervoso) (Daleck \& Nardi, 2016). Nos gatos, a forma mediastinal e alimentar são mais comuns que a multicêntrica e a extranodal (Couto, 2000), porém com o surgimento da vacina contra leucemia viral felina (FeLV), houve um decréscimo no número de felinos com linfoma mediastinal, assim para Wilson (2008) o linfoma alimentar passa a ser sozinho a forma mais comum nos gatos, sendo que geralmente ele não está associado a infecções por retrovírus e acomete animais mais velhos.

\section{Relato de caso e discussão}

Gato, macho, castrado, 1 ano de idade, sem raça definida, pesando $4,9 \mathrm{~kg}$, foi atendido por colega veterinário apresentando como única queixa principal aumento de linfonodos periféricos (submandibulares, inguinais e poplíteos), foi solicitado pelo colega hemograma, ultrassonografia abdominal, citologia de linfonodo e teste rápido para FIV/FeLV. Segundo Andrade (2006), em cães a ocorrência de linfoma multicêntrico é muito comum, já Couto (2001) refere que essa forma de linfoma é pouco frequente nos felinos domésticos.

Couto (2001) também diz que quando o linfoma multicêntrico ocorre nos felinos pode levar a obstruções mecânicas, resultando em edemas, dispneia, tosse, e o animal muitas vezes se apresenta letárgico. Mas para Junior et al. (2008), a linfadenomegalia é o principal sinal quando se suspeita de linfoma multicêntrico, sendo ela bilateral dos linfonodos superficiais (principalmente poplíteo, submandibular, pré-escapular e axilar). $O$ paciente em questão era bem ativo e tinha somente a linfadenomegalia como sinal, confirmando o que foi dito por Junior et al. (2008). O paciente não apresentava dor à palpação dos linfonodos e os mesmos tinham consistência firme e eram móveis, corroborando o que diz Morris (2007) "os linfonodos são aumentados e firmes, mas usualmente não são doloridos a palpação".

No eritrograma foi achado uma discreta eritrocitose e hiperproteinemia, a contagem de plaquetas mostrou uma trombocitopenia, já no leucograma houve uma discreta leucopenia, por neutropenia e linfopenia. Jain (1993) cita que no hemograma de pacientes com linfoma um achado frequente é a presença de uma anemia normocítica normocrômica decorrente da liberação de fatores neoplásicos que deprimem a eritropoiese. Vail (2013) cita que o animal pode ou não ter anemia, acompanhada de trombocitopenia e leucopenia, e que a hiperglobulinemia pode ocorrer em linfomas de linfócito B.

Foi solicitado para o paciente ELISA para FIV/FeLV e o resultado foi negativo para ambas retroviroses. Segundo Rojko et al. (1989), na década de 70, cerca de 70\% dos linfomas felinos foram associados à infecção progressiva pelo FeLV, nos EUA. No caso em questão o paciente era FeLV negativo no teste de ELISA, mas não foi realizado a PCR para identificar o DNA do provirus do FeLV que poderia indicar uma infecção regressiva, e alguns estudos evidenciam a ocorrência de linfomas em gatos com infecção regressiva, um estudo realizado por Jackson et al. (1993) apontaram que dos 70 casos de linfomas em gatos, $30 \%$ eram negativos no ELISA e positivos na PCR.

A ultrassonografia abdominal do paciente revelou esplenomegalia e linfadenomegalia de linfonodo hepático $(0,96 \mathrm{~cm} \times 0,86 \mathrm{~cm})$, pancreatoduodenal $(1,26 \mathrm{~cm} \times 0,69 \mathrm{~cm})$, iliacomedial direito $(3,48 \mathrm{~cm} \times$ $1,41 \mathrm{~cm})$ e esquerdo $(3,59 \mathrm{~cm} \times 0,96 \mathrm{~cm})$, cólico $(1,87 \mathrm{~cm} \times 0,72 \mathrm{~cm})$, mesentérico $(2,90 \mathrm{~cm} \times 0,74 \mathrm{~cm})$, inguinal direito $(2,36 \mathrm{~cm} \times 1,32 \mathrm{~cm})$ e esquerdo $(1,78 \mathrm{~cm} \times 1,52 \mathrm{~cm})$. Para Vail \& DH (2004) o diagnóstico por imagem auxilia na determinação da extensão da doença, o que pode influenciar no prognóstico final e na decisão de prosseguir com a terapia. 
Foi coletado material de linfonodo submandibular esquerdo para citopatologia e o resultado foi sugestivo de linfoma imunoblástico com seguinte descrição pelo patologista: "Amostra citológica revela presença de acentuada quantidade de linfócitos com acentuada anisocitose e anisocariose, cromatina celular ligeiramente grosseira, nucléolo evidente, único, arredondado e grande, disposto centralmente, além de ocasionais células apresentando dois nucléolos, citoplasma basofílico e com quantidade variada. Nota-se a presença de acentuada quantidade de hemácias e corpúsculos linfoglandulares, células apresentando mitose". Para Henry \& Higginbotham (2009), a citologia permite identificar rapidamente as populações linfocitárias anormais, mas para Couto (2009) alguns casos de linfoma multicêntrico, a citologia do linfonodo às vezes pode ser insuficiente devido à dificuldade em distinguir linfoma de hiperplasia benigna do linfonodo, nestes animais é melhor a excisão total do linfonodo para análise histopatológica.

Os linfomas de baixo grau são formados por células pequenas com baixo índice mitótico, que normalmente progridem lentamente e por isso são menos responsivos à quimioterapia, a remissão da neoplasia pode ser alcança passadas várias semanas ou pode não chegar a ser completa, porém os linfomas de baixo grau estão associados a tempos de sobrevivência maiores Vail (2013). No caso dos linfomas de alto grau de malignidade, eles apresentam um índice mitótico elevado e respondem positivamente à quimioterapia, normalmente mostram uma remissão completa. O problema com os linfomas de alto grau é que podem desenvolver facilmente resistência quimioterápica devido ao seu elevado potencial para o aparecimento de mutações que favorece a sobrevivência de células com elevado índice mitótico. Linfomas com este grau de malignidade mostram uma rápida progressão, causando a morte do animal se nenhuma terapia efetiva for rapidamente realizada (Vail, 2013).

Após o diagnóstico de linfoma de alto grau o paciente deu entrada no Hospital Veterinário escola da Universidade Guarulhos para uma segunda opinião e possível tratamento. Na anamnese a tutora relatou aumento dos linfonodos periféricos como a única alteração perceptível, em casa o animal estava ativo e apresentava normorexia, normodipsia, normoquezia. No exame físico o animal estava alerta, apresentava-se hidratado, mucosas normocoradas e hipertermia $\left(39,8{ }^{\circ} \mathrm{C}\right)$, o paciente não tinha sensibilidade dolorosa à palpação abdominal e houve confirmação da linfadenomegalia periférica. Com base no diagnóstico citopatológico instituiu-se o tratamento quimioterápico, cujo protocolo adotado foi o CHOP (ciclofosfamida, doxorrubicina, vincristina e prednisolona) por 24 semanas. Os protocolos utilizados nos EUA são, na sua maioria, modificações do protocolo humano CHOP [ciclofosfamida, doxorrubicina, vincristina $\left(\right.$ Oncovin $\left.^{\circledR}\right)$ e prednisolona], como mostra a tabela 1, já na Europa é mais comum o uso do COP [ciclofosfamida, vincristina $\left(\right.$ Oncovin ${ }^{\circledR}$ ) e prednisolona] (Withrow, 2007).

Tabela 1. Protocolo quimioterápico CHOP.

\begin{tabular}{lccc}
\hline Semana & Fármaco & Dose & Via \\
\hline 1 & Vincristina/Prednisolona & $0,75 \mathrm{mg} / \mathrm{m}^{2} ; 2 \mathrm{mg} / \mathrm{kg}$ & IV/VO \\
2 & Ciclofosfamida/Prednisolona & $300 \mathrm{mg} / \mathrm{m}^{2} ; 1,5 \mathrm{mg} / \mathrm{kg}$ & VO/VO \\
3 & Vincristina/Prednisolona & $0,75 \mathrm{mg} / \mathrm{m}^{2} ; 1 \mathrm{mg} / \mathrm{kg}$ & IV/VO \\
4 & Doxorrubicina/Prednisolona & $25 \mathrm{mg} / \mathrm{m}^{2} ; 0,5 \mathrm{mg} / \mathrm{kg}$ & IV/VO \\
\hline
\end{tabular}

*Repetir o protocolo até completar 24 semanas (A prednisolona será retirada após as 4 primeiras semanas).

Tendo em vista que o linfoma é uma neoplasia sistêmica, a base do tratamento é a quimioterapia, o uso adequado da mesma promove aumento da longevidade e da qualidade de vida dos pacientes oncológicos, e em alguns casos até alcança a cura completa do câncer (Couto, 2001). O tratamento quimioterápico tem como objetivo induzir a remissão completa e duradoura da neoplasia, e em casos de recidiva, reinduzir a sua remissão (Withrow, 2007).

A ciclofosfamida faz parte do grupo de fármacos citotóxicos ou antineoplásicos que impossibilitam a replicação celular, além disso, esse fármaco causa mielossupressão, então é indicado a monitorização do paciente através de hemogramas (Moore \& Frimberger, 2009). A doxorrubicina é recomendada em infusão contínua de solução salina a $0,9 \%$ durante 20 minutos, seu extravasamento provoca necrose tecidual (Ogilvie \& Moore, 2001). Esse fármaco requer monitorização por hemograma, perfil renal e hepático, além do controle de sinais gastrintestinais (êmese e colite). É importante salientar que os gatos são menos tolerantes à doxorrubicina do que os cães (Crystal \& Schmidt, 2011). A vincristina impede a 
formação do fuso mitótico durante o processo de mitose da célula tumoral. Sua administração é endovenosa e pode causar necrose em caso de extravasamento, sua utilização deve ser acompanhada com realização de hemograma (Ogilvie \& Moore, 2001). Os imunomoduladores como os corticoides são fármacos que alteram a resposta imunológica do paciente e podem ser utilizados no tratamento das neoplasias. A prednisolona têm efeitos linfolíticos e são capazes de suprimir a mitose dos linfócitos (Ogilvie \& Moore, 2001).

Após dois meses de quimioterapia o paciente já apresentava remissão completa dos linfonodos periféricos, porém o tratamento teve que se estender, já que o animal apresentou alguns episódios de intensa leucopenia, necessitando a suspensão do protocolo quimioterápico por, no mínimo, sete dias. Apesar da intensa leucopenia, o animal nunca apresentou outros efeitos colaterais em decorrência da quimioterapia.

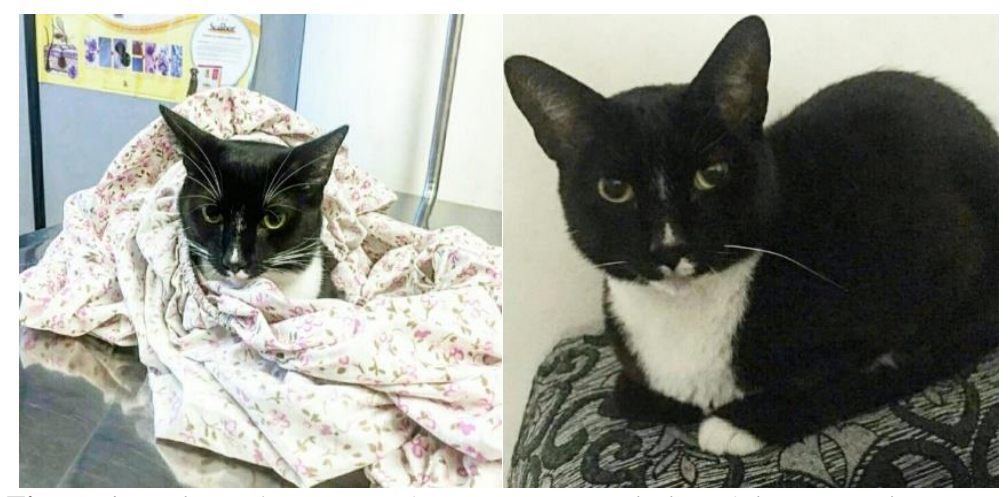

Figura 1. Paciente durante e após o tratamento quimioterápico respectivamente.

O paciente concluiu as 24 semanas do protocolo quimioterápico e alguns dias após a última sessão foi coletado um hemograma, perfil hepático e realizado ultrassonografia abdominal. No hemograma apenas a parte do leucograma havia alteração: leucopenia por neutropenia e linfopenia, no perfil hepático não houve alterações e na ultrassonografia abdominal também não havia nada digno de nota, indicando a remissão da linfadenomegalia do primeiro ultrassom.

$\mathrm{O}$ animal recebeu alta do tratamento e passaria para um acompanhamento trimestral para reavaliar o estado geral e se haveria recidiva do tumor. Após meses da alta da quimioterapia o paciente foi a óbito, a tutora relata que o animal ficou dispneico durante a noite e a mesma o colocou no automóvel para ir a um serviço veterinário 24 horas, mas o animal não resistiu até a chegada ao hospital. $\mathrm{O}$ corpo não foi enviado à necropsia por escolha da tutora, então não foi possível saber se houve recidiva do tumor, metástase ou se o óbito teve outra causa desconhecida.

\section{Conclusão}

Com o seguinte trabalho pode-se concluir que a ocorrência de linfoma multicêntrico não é tão comum na espécie felina, mas pode ocorrer, por isso é preciso ter conhecimento da neoplasia para dar orientação correta ao tutor e tratamento adequado para o paciente. Apesar de o exame físico ser valioso e nos sugerir linfoma multicêntrico, é valido salientar a importância do diagnóstico definitivo por meio de citologia elou biópsia seguida de histopatológico.

É fundamental testar o felino com linfoma para FIV $\backslash F e L V$ já que ambas retroviroses tem papéis importantes como indutoras de linfoma. Gatos com infecções progressivas por FeLV possuem $62 \%$ mais chance de desenvolver linfoma, e alguns novos estudos apontam que talvez a infecção regressiva por FeLV também possa estar associada com o surgimento de linfoma.

A terapia com múltiplos quimioterápicos tende a ter uma resposta melhor do que a terapia com um único fármaco isolado, sendo um dos protocolos mais utilizados o CHOP (ciclofosfamida, doxorrubicina, vincristina e prednisolona).

O prognóstico para linfomas é reservado, sendo que o linfoma de alto grau é mais responsivo a quimioterapia, porém o paciente tem uma sobrevida menor, se comparado ao linfoma de baixo grau. 


\section{Referências bibliográficas}

Andrade, F. C. (2006). Linfoma multicêntrico em cães: relato de caso. In Monografia (especialização) (pp. 1-22). http://repositorio.ufsm.br/handle/1/1032

Choy, K., \& Bryan, J. N. (2016). Linfoma. In: O Gato: Medicina Interna. 1. ed. [S. 1.]: ROCA. v. 1, cap. 28

Couto, C. G. (2009). Lymphoma in the cat and dog. In Nelson, R.N. \& Couto, C.G. (Eds). Small animal internal medicine. (Elsevier., ed.). Missouri: Mosby.

Couto, C. Guillermo. (2001). What is New on Feline Lymphoma? Journal of Feline Medicine and Surgery, 3(4), 171-176. https://doi.org/10.1053/jfms.2001.0146

Couto, C Guillermo. (2000). Advances in the Treatment of the Cat with Lymphoma in Practice. Journal of Feline Medicine and Surgery, 2(2), 95-100. https://doi.org/10.1053/jfms.2000.0079

Crystal, M. A., \& Schmidt, B. R. (2011). Chemotherapy for lymphoma. In B. P. Ltd. (Ed.), The Feline Patient. (4 ed., pp. 76-80). Blackwell Publishing Ltd.

Daleck, C. R., \& Nardi, A. B. (2016). Oncologia em cães e gatos . Grupo Gen-Editora Roca Ltda. Cap 31, p.633.

Henry, C. J., \& Higginbotham, M. L. (2009). Cancer Management in Small Animal Practice - E-Book.

Jackson, M. L., Haines, D. M., Meric, S. M., \& Misra, V. (1993). Feline leukemia virus detection by immunohistochemistry and polymerase chain reaction in formalin-fixed, paraffin-embedded tumor tissue from cats with lymphosarcoma. Canadian Journal of Veterinary Research, 57(4), 269-276. http://www.ncbi.nlm.nih.gov/pubmed/8269365

Jain, N. C. (1993). Comparative hematology of common domestic animals. Essentials of Veterinary Hematology, 1, 19-53.

Junior, A. M. S., Silva, T. D. P., Helou, J. B., \& Soares, L. K. (2008). Linfoma Multicêntrico em Onça Preta (Panthera onca) - relato de caso. Conbravet.

Moore, A. S., \& Frimberger, A. E. (2009). Anticancer drugs and protocols: traditional drugs. Moore \& Frimberger, JD \& Twedt, DC (Eds.), Kirk's Current Veterinary Therapy XIV. Missouri: Saunders Elsevier, 309-311.

Morris, J. (2007). Sistema hematopoiético. In: Oncologia em pequenos animais. Editora Roca. cap. 15. p.229-252.

Ogilvie, G. K., \& Moore, A. S. (2001). Feline oncology. Veterinary Learning Systems.

Rojko, J. L., Kociba, G. J., Abkowitz, J. L., Hamilton, K. L., Hardy, W. D., Ihle, J. N., \& O’Brien, S. J. (1989). Feline lymphomas: immunological and cytochemical characterization. Cancer Research, 49(2), 345-351.

Vail, D. M. (2013). Canine lymphoma and lymphoid leukemias. Feline lymphoma and leukemia. In Withrow \& MacEwen's small animal clinical oncology. Saint Louis, Mo: Saunders (pp. 608-650).

Vail, D. M., \& DH, T. (2004). Tumores hematopoiéticos. Ettinger, SJ; Feldman, EC Tratado de Medicina Interna Veterinária. $5^{a}$ Ed. Rio de Janeiro: Guanabara Koogan, 538-544.

Wilson, H. M. (2008). Feline Alimentary Lymphoma: Demystifying the Enigma. Topics in Companion Animal Medicine, 23(4), 177-184. https://doi.org/10.1053/j.tcam.2008.10.003

Withrow, S. J. (2001). Small Animal Oncology (3rd Edition), ed.). Filadelfia W.B. Saunders Company.

Withrow, S. J. (2007). Feline lymphoma and leucemia. In: Withrow and MacEwen's small animal clinical oncology. Elsevier Health Sciences.

Yazbek, K. V. B. (2008). Avaliação da dor e da qualidade de vida em cães com câncer. Revista Dor, São Paulo, 9(3), 1297-1304.

Recebido: 25 de junho, 2020.

Aprovado: 5 de agosto, 2020.

Disponível online: 10 de setembro, 2020.
Licenciamento: Este artigo é publicado na modalidade Acesso Aberto sob a licença Creative Commons Atribuição 4.0 (CC-BY 4.0), a qual permite uso irrestrito, distribuição, reprodução em qualquer meio, desde que o autor e a fonte sejam devidamente creditados. 